Vinicius Ribeiro Pereira

Métodos Alternativos no Critério Brasil para Construção de Indicadores Sócio-Econômico: Teoria da Resposta ao Item

Dissertação de Mestrado

Departamento de Engenharia Elétrica Programa de Pós-Graduação em Engenharia Elétrica 
Vinicius Ribeiro Pereira

\section{Métodos Alternativos no Critério Brasil para Construção de Indicadores Sócio-Econômico: Teoria da Resposta ao Item}

Dissertação apresentada como requisito parcial para obtenção do grau de Mestre pelo Programa de Pósgraduação em Engenharia Elétrica do Departamento de Engenharia Elétrica da PUC-Rio.

Orientador: Prof. Reinaldo Castro Souza

Co-orientador: Prof. Tufi Machado Soares 


$$
\begin{array}{r}
\text { Pontifícia Universidade Católica } \\
\text { do Rio de Janeiro }
\end{array}
$$

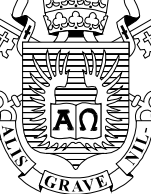

Vinicius Ribeiro Pereira

\begin{abstract}
Métodos Alternativos no Critério Brasil para Construção de Indicadores Sócio-Econômico: Teoria da Resposta ao Item
\end{abstract}

Dissertação de Mestrado apresentada como requisito parcial para obtenção do grau de Mestre pelo Programa de Pós-Graduação em Engenharia Elétrica do Departamento de Engenharia Elétrica do Centro Técnico Científico da PUC-Rio. Aprovada pela Comissão Examinadora abaixo assinada.

Dr. Reinaldo Castro Souza

Orientador

Departamento de Engenharia Elétrica - PUC-Rio

Dr. Tufi Machado Soares

UFJF

Dr. Paulo César de Mendonça Motta

Instituto de Administração e Gerência - PUC-Rio

Dr. Marcos Azevedo da Silveira

Departamento de Engenharia Elétrica - PUC-Rio

Prof. José Eugenio Leal Coordenador Setorial do Centro

Técnico Científico - PUC-Rio

Rio de Janeiro, 22 de julho de 2004 
Ficha catalográfica

Pereira, Vinicius Ribeiro

Métodos alternativos no critério Brasil para construção de indicadores sócio-econômico: teoria da resposta ao item / Vinicius Ribeiro Pereira ; orientador: Reinaldo Castro Souza ; co-orientador: Tufi Machado Soares. - Rio de Janeiro : PUC-Rio, Departamento de Engenharia Elétrica, 2004.

103 f. ; $30 \mathrm{~cm}$

Dissertação (mestrado) - Pontifícia Universidade Católica do Rio de Janeiro, Departamento de Engenharia Elétrica.

Inclui referências bibliográficas

1. Engenharia elétrica - Teses. 2. Teoria da resposta ao item. 3. Modelos multidimensionais. 4. Status sócioeconômico. I. Souza, Reinaldo Castro. II. Soares, Tufi Machado. III. Pontifícia Universidade Católica do Rio de Janeiro. Departamento de Engenharia Elétrica. III. Título.

CDD: 621.3 


\section{Agradecimentos}

Em primeiro lugar a Deus por me guiar nos estudos e em toda minha carreira acadêmica, bem como na minha vida particular.

Ao meu co-orientador professor Tufi Machado Soares pela confiança que depositou em meu trabalho e pela disponibilidade e paciência a qual sempre teve comigo.

Ao meu orientador professor Reinaldo Castro Souza pela amizade e confiança que é recíproca.

Aos jesuítas da PUC-Rio que contribuíram para minha formação acadêmica.

Aos meus amigos Ude, Vó, Cristiano, Tião, Wesley, Flavinha, Cris, Felipão, Ana Paiva, Flávio, Zanini, Luciana Arruda, Bernardo e tantos outros que contribuíram de alguma forma para que eu terminasse esta dissertação.

A minha família, meu pai Valter e minha irmã Viviane por estarem ao meu lado. E especialmente a minha mãe Rita, pelas suas incansáveis orações.

A minha futura esposa Patrícia, pela paciência e dedicação.

Aos professores Paulo César Motta e Marcos da Silveira pela disponibilidade de participarem da banca examinadora bem como as suas sugestões para enriquecimento da dissertação.

A CAPES pelo auxílio concedido. 


\section{Resumo}

Pereira, Vinicius Ribeiro; Souza, Reinaldo Castro (Orientador); Soares, Tufi Machado (Co-orientador). Métodos Alternativos no Critério Brasil para Construção de Indicadores Sócio-econômico: Teoria da Resposta ao Item, 2004, 103 p. Dissertação de Mestrado - Departamento de Engenharia Elétrica, Pontifícia Universidade Católica do Rio de Janeiro.

No Brasil a teoria da Resposta ao Item (TRI) tem sido empregada principalmente na produção de índices de proficiência para alunos que participam de testes de avaliação educacional em larga escala. No entanto, seus diferentes modelos permitem construir indicadores com as mais variadas finalidades, e este é o caso dos indicadores de condição sócio econômica. Existem poucos estudos no Brasil que abordam técnicas empregadas para a produção de indicadores da condição sócio-econômica tendo como base a teoria da resposta ao item. Neste trabalho, propõe-se construir outros tipos de indicadores da classificação sócioeconômica, além do Critério Brasil, utilizando-se modelos específicos da Teoria da Resposta ao Item. Esses indicadores serão comparados, interpretados, e comparados com o indicador do Critério Brasil.

\section{Palavras-chave}

Teoria da Resposta ao Item, Modelos Multidimensionais, Status SócioEconômico. 


\section{Abstract}

Pereira, Vinicius Ribeiro; Souza, Reinaldo Castro (Advisor); Soares, Tufi Machado (Co-Advisor). Alternatives Models for production socialeconomical index: Item Responde Theory, 2004, 103 p. Dissertação de Mestrado - Departamento de Engenharia Elétrica, Pontifícia Universidade Católica do Rio de Janeiro.

The IRT (Item Response Theory) has been used in Brazil mainly in the production of proficiency indices related to large scale educational assessment. However, the distinct models include in the formulation allow broader applications in the construction of indices, as; for instance, social-economical index (SEI). These are only a few published studies on techniques to formulates SEI specially those using the IRT. In this paper it is proposed a new formulation for the SEI in Brazil based on the IRT the obtained index is compared with the official one, knows as "Critério Brasil".

\section{Keywords}

Item Response Theory, Multidimensional Model, Socio-Economic Status. 


\section{Sumário}

1. Introdução 11

1.1 - Estrutura da dissertação 13

2. Metodologia e Critérios Empregados no Brasil para Classificar os Estratos Sociais

2.1 - Considerações Gerais 14

2.2 - Para que um Índice que Avalia a Condição Sócio Econômica? 14

$\begin{array}{ll}2.3 \text { - Origem e Histórico } & 15\end{array}$

2.3.1 - Antecedentes do Sistema ABA/ABIPEME (1982) 14

2.3.2 - Qual a Razão de Tanta Controvérsia? 16

2.3.3 - Uma Abordagem Histórica 18

2.3.4 - Segundo Estudo para Reformulação do Critério ABA 19

2.4 - O Método Utilizado 20

2.4.1- Critério ABA/ ABIPEME (1982) 20

2.4.2 - Critério de Classificação Econômica Brasil (2003) - CCE 23

2.5 - Uma Comparação entre os Métodos ABA/ABIPEME e CCEB 24

2.6 - Considerações Finais 26

3. Traços Latentes e a Teoria de Resposta ao Item -TRI 28

3.1 - Modelos da Curva Característica do Item - CCI 30

3.2 - Comentário 31

3.3 - Teoria de Resposta ao Item - TRI 31

3.4 - O contexto das Avaliações Educacionais 33

3.5 - Hipóteses Básicas $\quad 34$

$\begin{array}{ll}3.6 \text { - Modelos } & 35\end{array}$

3.6.1 - Modelos Unidimensionais para Itens Dicotômicos 35

3.7 - Modelos para Itens com Formato de Resposta Politômica 39

3.8 - Estimação dos Parâmetros 42

3.9 - Métodos Clássicos para Discriminação dos Itens e Análise da Dimensionalidade 43

3.9.1 - Correlação Bisserial e Correlação Ponto Bisserial 43

3.9.2 - Correlação Polisserial e Ponto Polisserial 46

4. A Produção do Indicador Sócio Econômico via Teoria da Resposta ao Item (TRI) 48

4.1 - Índices Para o Padrão de Vida 49

4.1.1 - Introdução $\quad 49$

4.2 - Índice Obtido a Partir de Modelos para Respostas Graduadas 52

5. Resultados e Interpretação do Índice Construído 56

5.1 - Escalas $\quad 56$

5.2 - Leitura das Escalas para Todos os Itens $\quad 58$

5.3 - Critério Brasil versus TRI 61

5.4 - Análise de Regressão 63 
6. Alternativas aos Modelos Clássico da TRI

6.1 - Modelos de Classes Latentes para Análise de Agrupamentos (L C Cluster)

6.2 - Resultados no Uso do LC cluster

7. Conclusões e Considerações Finais

8. Bibliografia

Anexos

82

Anexo 1 - Modelo Clássico de Análise Fatorial $\quad 83$

Anexo 2 - Tabelas Descritivas para os Itens $\quad 89$

Anexo 3 - Tabelas com as Respectivas Probabilidades 93

Anexo 4 - Matriz de Componentes Principais 97

Anexo 5 - Gráficos Gerados a partir do Modelo de Respostas Graduadas 98 


\section{Lista de figuras}

Figura 1 - Curva característica do item

Figura 2 - Curva característica do item com mesma discriminação e diferentes dificuldades

Figura 3 - Curva com dificuldades iguais, porém com diferentes discriminações

Figura 4 - Curva característica do item com valores especificados 38

Figura 5 - Modelo de respostas graduadas para o item banheiro 41

Figura 6 - Matriz de componentes principais 97

Figura 7 - Variância total explicada 55

Figura 8 - Interpretabilidade para leitura dos scores estimados 56

Figura 9 - Histograma dos scores estimados $\quad 59$

Figura 10 - Normal Q-Q Plot dos scores estimados 60

Figura 11 - Box-Plot dos scores estimados 60

Figura 12 - Comparação entre o Critério Brasil e os scores estimados via TRI

Figura 13 - Análise de regressão

Figura 14 - Característica das posses de um indivíduo que pertence a um determinado cluster

Figura 15 - LC cluster versus TRI

Figura 16 - LC cluster versus Critério Brasil 76

Figura 17 - Os três critérios 


\section{Lista de tabelas}

Tabela 1 - Critério ABA-Abipeme (1982) 22

Tabela 2 - Pontuação para grau de instrução ABA-Abipeme (1982) 22

Tabela 3 - Pontuação de corte ABA-Abipeme (1982) 22

Tabela 4 - Pontuação do Critério Brasil 23

Tabela 5 - Pontuação para grau de instrução do Chefe de família no Critério Brasil $\quad 24$

Tabela 6 - Pontuação do corte no Critério Brasil 24

Tabela 7 - Pontos atribuídos a automóvel pelos critérios ABA/ABIPEME e CCEB 25

Tabela 8 - Pontos atribuídos a empregada mensalista pelos critérios ABA/ABIPEME e CCEB 25

Tabela 9 - Pontos atribuídos ao aspirador de pó pelos critérios ABA/ABIPEME e CEB 25

Tabela 10 - Questões utilizadas na construção do índice 51

Tabela 11 - Resultados das correlações de Pearson e Polisserial 52

Tabela 12 - Parâmetros dos itens $\quad 53$

Tabela 13 - Interpretabilidade dos scores estimados para o item $\begin{array}{ll}\text { estrutura da casa } & 57\end{array}$

Tabela 14 - Interpretabilidade para leitura (uma $2^{\mathrm{a}}$. opção) dos scores estimados 58

Tabela 15 - Comparação entre o Critério Brasil e os scores estimados via TRI 61

Tabela 16 - Valores dos percentis 63

Tabela 17 - Resultado dos valores de significância das variáveis para o $\begin{array}{ll}\text { modelo LC cluster } & 70\end{array}$

Tabela 18 - Possibilidades de pertinência a um determinado cluster $\quad 74$

Tabela 19 - Probabilidade de um indivíduo com determinadas posses $\begin{array}{ll}\text { pertencer a cada um dos clusters } & 96\end{array}$ 